\title{
Binding-protein-dependent Sugar Transport by Agrobacterium radiobacter and A. tumefaciens Grown in Continuous Culture
}

\author{
By ALEX CORNISH, JACQUELINE A. GREENWOOD \\ AND COLIN W. JONES* \\ Department of Biochemistry, University of Leicester, Leicester LEI 7RH, UK
}

(Received 27 June 1989; revised 9 August 1989; accepted 14 August 1989)

\begin{abstract}
Binding-protein-dependent sugar transport has been investigated in Agrobacterium radiobacter and $A$. tumefaciens. A. radiobacter contained two high-affinity glucose-binding proteins (GBP1 and GBP2) that additionally bound D-galactose $\left(K_{\mathrm{D}} 0.26 \mu \mathrm{M}\right)$ and D-xylose $\left(K_{\mathrm{D}} 0.04 \mu \mathrm{M}\right)$ respectively and were involved in the transport of these sugars. Partial sequencing of GBP1 and GBP2 showed that GBP2 exhibited significant homology with both the arabinose-binding protein (ABP) and the galactose-binding protein (GalBP) from Escherichia coli, whereas GBP1 exhibited significant homology only with ABP. Antiserum raised against GBP1 cross-reacted with GBP1 but not with GBP2, and vice versa. Anti-GBP1 and anti-GBP2 also cross-reacted with proteins corresponding to GBP1 and GBP2 respectively in $A$. tumefaciens, but little or no cross-reaction was observed with selected members of the Enterobacteriaceae, Rhizobiaceae and Pseudomonadaceae families grown under glucose limitation. GBP1 was less strongly repressed than GBP2 following batch growth of $A$. radiobacter on various carbon sources. The growth of $A$. radiobacter for more than approximately 10 generations in continuous culture under galactose or xylose limitation $\left(D 0.045 \mathrm{~h}^{-1}\right)$ led to the emergence of new strains which exhibited increased rates of glucose/galactose or glucose/xylose uptake, and which respectively hyperproduced GBP1 (strain AR18a) or GBP2 (strain AR9a). Similarly, growth of $A$. tumefaciens for more than approximately 15 generations under glucose or galactose limitation produced new strains which exhibited increased rates of glucose/xylose or glucose/galactose uptake and which respectively hyperproduced proteins analogous to GBP2 (strain AT9) or GBP1 (strain AT18a). It is concluded that growth of Agrobacterium species under carbon-limited conditions leads to the predictable emergence of new strains which specifically hyperproduce the transport system for the limiting nutrient. The GBP1-dependent system of $\boldsymbol{A}$. radiobacter is unique amongst these transport systems in that the mutations that lead to its hyperproduction under carbon limitation render it least susceptible to repression by excess glucose during ammonia limitation, with the result that succinoglucan exopolysaccharide is produced from glucose at an enhanced rate.
\end{abstract}

\section{INTRODUCTION}

Agrobacterium radiobacter NCIB 11883 produces copious amounts of a succinoglucan exopolysaccharide when growth is limited by the availability of an anabolic substrate such as nitrogen, phosphorus or sulphur. Succinoglucan synthesis occurs at maximum rate during growth in continuous culture at low dilution rate under glucose-sufficient, ammonia-limited conditions (Linton et al., 1987a,b).

Glucose is actively transported into $A$. radiobacter by two osmotic-shock-sensitive systems, each of which contains a periplasmic glucose-binding protein (GBP1 and GBP2) (Cornish et al., $1988 a$ ). These systems are analogous to the binding-protein-dependent systems that transport

\footnotetext{
Abbreviations: ABP, arabinose-binding protein; GBP, glucose-binding protein; GalBP, galactose-binding protein.
} 
certain sugars, amino acids and inorganic ions into enteric bacteria (Ames, 1986; Henderson, 1986), and also to the binding-protein-dependent system that transports $\gamma$-butyrobetaine into Agrobacterium sp. (Nobile et al., 1988).

GBP1 and GBP2 are maximally produced by $A$. radiobacter during glucose-limited growth, as also is a third periplasmic protein (BP3) whose function is currently unknown. Prolonged growth of the wild-type organism under glucose limitation has led to the emergence of two new strains (AR18 and AR9), which hyperproduce GBP1 and GBP2 respectively and presumably arise by spontaneous mutation in response to severe nutrient starvation. The GBP1-dependent glucose transport system is less strongly repressed than the GBP2-dependent system during ammonialimited growth, and this is reflected in a significantly higher rate of succinoglucan production by strain AR18 compared with the wild-type or strain AR9. Flux control analysis has confirmed that glucose transport is a major kinetic control point in the pathway of exopolysaccharide synthesis by $A$. radiobacter (Cornish et al., 1988b).

This paper describes some of the sugar-binding, structural and immunological properties of GBP1 and GBP2 from $A$. radiobacter, and shows that continuous culture can be used in a rational manner to select other novel strains of $A$. radiobacter (and its close relative A. tumefaciens) that predictably hyperproduce GBP1- or GBP2-dependent transport systems.

\section{METHODS}

Organisms. Agrobacterium radiobacter NCIB 11883, Xanthomonas campestris ATCC 13951 (Rye et al., 1988), Rhizobium leguminosarum T1105, Erwinia herbicola NCIB 12495 (Linton et al., 1988), Pseudomonas aeruginosa ATCC 10145 and Pseudomonas mendocina NCIB 11687 were obtained from Shell Research Ltd, Sittingbourne, Kent, UK. Escherichia coli K12 and Klebsiella pneumoniae M5al were provided by R. A. Cooper, Department of Biochemistry, University of Leicester, UK. A. tumefaciens T37 was obtained from J. Draper, Department of Botany, University of Leicester, UK. The isolation of Agrobacterium radiobacter strains AR9 and AR 18 has been described previously (Cornish et al., 1988a). All of the organisms were stored in $20 \%(\mathrm{v} / \mathrm{v})$ glycerol at $-20^{\circ} \mathrm{C}$.

Growth conditions. Batch culture was done in $500 \mathrm{ml}$ baffled flasks containing $150 \mathrm{ml}$ minimal medium (pH 7.0) supplemented with glucose $\left(5 \mathrm{~g} \mathrm{l}^{-1}\right)$ (Linton et al., 1987a). Ammonium sulphate $\left(3 \mathrm{~g} \mathrm{l}^{-1}\right)$ was used as the nitrogen source for all organisms except $X$. campestris, where it was replaced by monosodium glutamate $\left(6 \mathrm{~g}^{-1}\right)$. Calcium carbonate $\left(3 \mathrm{~g} \mathrm{t}^{-1}\right)$ was added to the Erwinia medium to maintain the $\mathrm{pH}$ at approximately $7 \cdot 0$. The growth temperature was $30^{\circ} \mathrm{C}$ except for $E$. coli and $X$. campestris which were grown at $37^{\circ} \mathrm{C}$ and $28^{\circ} \mathrm{C}$ respectively. The cultures were aerated by shaking, and cells were harvested during the exponential growth phase.

For glucose-limited fed-batch culture, exponentially growing cultures were harvested, washed in glucose-free growth medium and then used to inoculate $150 \mathrm{ml}$ of the same medium (initial cell density $0 \cdot 1 \mathrm{~g}$ dry wt $\mathrm{l}^{-1}$ ). Sterile glucose solution $\left(1.9 \mathrm{~g} \mathrm{l}^{-1}\right)$ was continuously pumped into the medium at a low rate to give an initial specific growth rate of approximately $0.1 \mathrm{~h}^{-1}\left(0.05 \mathrm{~h}^{-1}\right.$ for $X$. campestris). Cells were harvested when the cell density of the culture had increased by approximately fourfold.

Continuous cultures $\left(D 0.045 \mathrm{~h}^{-1}\right)$ of $A$. radiobacter and $A$. tumefaciens were grown at $30^{\circ} \mathrm{C}$ under carbon limitation as described previously (Cornish et al., 1988a). In order to achieve ammonia-limited growth the input concentration of the carbon source was increased from 1.9 to $16 \mathrm{~g}^{-1}$ and the concentration of ammonium sulphate was reduced from 3 to $0.5 \mathrm{~g} \mathrm{l}^{-1}$.

Single-colony analysis. Samples were withdrawn from the chemostat, streaked out on glucose-minimal agar and incubated at $30^{\circ} \mathrm{C}$ for $48 \mathrm{~h}$. Twenty-four colonies were then picked off and grown individually in $3 \mathrm{ml}$ minimal medium containing $1 \mathrm{~g}$ glucose $\mathrm{l}^{-1}$. The cells were harvested after growth had finished and their protein profiles were analysed using SDS-PAGE.

Preparation of antisera. GBP1 and GBP2 were purified by FPLC from shock fluids prepared from A. radiobacter which had been grown under glucose limitation $\left(D 0.045 \mathrm{~h}^{-1}\right.$; Cornish et al., 1988a). Minor impurities were subsequently removed using preparative SDS-PAGE followed by electro-elution. The pure proteins $(300 \mu \mathrm{g})$ were injected into New Zealand White rabbits at fortnightly intervals for 2 months using Freund's complete adjuvant for the first injection and incomplete adjuvant thereafter. Blood samples $(10 \mathrm{ml})$ were taken 2 weeks after each injection, erythrocytes were removed by centrifugation and the resultant serum was stored at $-20^{\circ} \mathrm{C}$.

SDS-PAGE and Western blotting. Discontinuous slab-gel electrophoresis of proteins was done using $12 \cdot 5 \%(\mathrm{w} / \mathrm{v})$ polyacrylamide gels. Suspensions of bacteria were boiled for $4 \mathrm{~min}$ in dissolving buffer (Laemmli, 1970) and a volume containing approximately $20 \mu \mathrm{g}$ protein was loaded into each gel track. Gels were run in duplicate so that one was stained for proteins using Kenacid Blue whilst the contents of the other were transferred onto nitrocellulose sheets using an LKB Novablot apparatus operated according to the manufacturer's instructions. The following proteins were used as $M_{\mathrm{r}}$ standards: $\alpha$-lactalbumin, $\left(M_{\mathrm{r}} 14200\right)$; trypsin inhibitor $(20100)$; 
trypsinogen (24000); carbonic anhydrase (29000); glyceraldehyde-3-phosphate dehydrogenase (36000); egg albumin (45000); and bovine albumin (66000). The $M_{\mathrm{r}}$ standards were located on the nitrocellulose sheets using Ponceau's Red stain which was subsequently washed off. Immunological staining for proteins that cross-reacted with antiserum raised to GBP1 or GBP2 was done using conventional procedures (Towbin et al., 1979).

Amino acid sequencing. N-Terminal amino acid sequencing was done using an Applied Biosystems model 470 gas-phase sequencer. Samples of the pure proteins (approximately $1 \mathrm{nmol}$ ) were sequenced after blotting onto a polyvinylidene difluoride disc. GBP2 sequenced readily, but the N-terminus of GBP1 was apparently blocked.

This latter problem was overcome by cleaving the protein into several fragments using staphylococcal $\mathrm{V} 8$

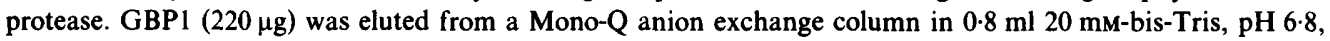
$140 \mathrm{mM}-\mathrm{KCl}$. A sample of the column eluate $(220 \mu \mathrm{g}$ in $0.8 \mathrm{ml})$ was boiled for $2 \mathrm{~min}$ in the presence of $0.1 \%$ SDS, cooled and then digested with V8 protease $(16 \mu \mathrm{g})$ for $2 \mathrm{~h}$ at $37^{\circ} \mathrm{C}$. SDS-PAGE sample buffer $(150 \mu \mathrm{l})$ was then added to the reaction mixture which was boiled for $2 \mathrm{~min}$. Proteolytic fragments were separated using SDS-PAGE and transferred electrophoretically on to a PVDF (polyvinylidene difluoride) membrane using the method of Matsudaira (1987), except that the buffer was $50 \mathrm{~mm}$-Tris/glycine $\mathrm{pH} 10 \cdot 0$, containing $10 \%(\mathrm{v} / \mathrm{v})$ methanol. The region of the membrane that contained a major polypeptide fragment of $M_{\mathrm{r}} 28000$ was then excised and sequenced.

Other methods. Uptake of sugars by washed cells, and association of sugars with pure binding proteins, were investigated as described previously (Cornish et al., 1988a). Succinoglucan concentrations were determined gravimetrically (Cornish et al., 1988b).

Presentation of data. Where appropriate data are given as the mean \pm SEM with the number of independent determinations given in parentheses.

Chemicals. Radiochemicals were purchased from Amersham. D-Glucose (AnalaR) was obtained from Fisons. D-Galactose ( $<0.01 \%$ D-glucose) and D-xylose were purchased from Sigma. All other reagents were obtained from Fisons and were of the highest grade available.

\section{RESULTS}

\section{Further characterization of periplasmic, glucose-binding proteins produced by $A$. radiobacter}

Binding studies carried out by exposing pure GBP1 and GBP2 to equilibrium dialysis in the presence of radiolabelled sugars showed that GBP1 bound D-glucose and D-galactose much more tightly than D-xylose, whereas GBP2 bound D-glucose and D-xylose much more tightly than D-galactose (Table 1). These results confirmed the earlier suggestion (Cornish et al., 1988a) that the absence of C-6 strongly reduced the strength of binding to GBP1 but not to GBP2 (D-xylose cf. D-glucose and D-galactose), whereas the presence of an axial hydroxyl group at C-4 of the pyranose ring substantially diminished the strength of binding to GBP2 but not to GBP1 (D-galactose cf. D-glucose and D-xylose). The results of these in vitro binding studies also raised the possibility that GBP1 and GBP2 might be involved in the transport of other sugars in vivo, particularly during carbon-limited growth (see below). None of the sugars tested bound to BP3.

Attempts were made to determine the N-terminal amino acid sequences of GBP1 and GBP2 in order to establish whether they showed any homology with periplasmic binding-proteins from $E$. coli. The N-terminal sequence of GBP2 posed no problems, but preliminary investigations with GBP1 indicated that the N-terminus was blocked; this has also been reported for the periplasmic $\gamma$-butyrobetaine-binding protein from Agrobacterium sp. (Nobile et al., 1988). However, it subsequently proved possible to generate proteolytic fragments from GBP1 using

\section{Table 1. Binding of D-glucose, D-galactose and D-xylose to pure GBP1 and GBP2 from}

\section{A. radiobacter}

Dissociation constants $\left(K_{\mathrm{D}}\right)$ were measured using equilibrium dialysis as described previously (Cornish et al., 1988a).

$\begin{array}{lcc}\text { Sugar } & \overbrace{\text { GBP1 }} & \text { GBP2 } \\ \text { D-Glucose } & 0.23 & 0.07 \\ \text { D-Galactose } & 0.26 & 480 \\ \text { D-Xylose } & 70 & 0.04\end{array}$


(a) ABP

(79)

GBP1 fragment

$\left(M_{\mathrm{r}} 28000\right)$

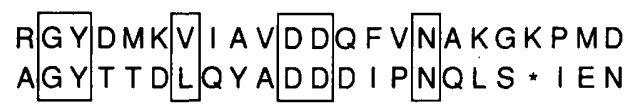

(b) $\mathrm{ABP}$

GBP2

GalBP

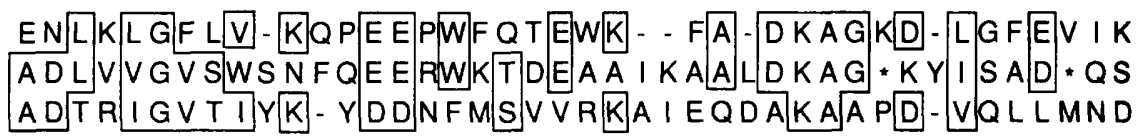

Fig. 1. Sequence homologies between glucose-binding proteins (GBP1 and GBP2) of $A$. radiobacter and the L-arabinose- and D-galactose-binding proteins of $E$. coli. (a) N-Terminal amino acid sequence of a proteolytic fragment $\left(M_{\mathrm{r}} 28000\right)$ derived from GBP1 compared with an internal region of the L-arabinose-binding protein (ABP) of $E$. coli. (b) N-Terminal amino acid sequence of GBP2 compared with the N-terminal regions of the L-arabinose- and D-galactose-binding (GalBP) proteins of E. coli. The proteins have been aligned with respect to each other according to Argos et al. (1981). Identical residues and conservative replacements $(\mathrm{I} / \mathrm{L} / \mathrm{V} ; \mathrm{S} / \mathrm{T} ; \mathrm{D} / \mathrm{E})$ are boxed. Residues which have not been assigned unambiguously in the sequences of the $A$. radiobacter proteins are indicated by asterisks $\left({ }^{*}\right)$.

staphylococcal V8 protease digestion, and one of these fragments $\left(M_{\mathrm{r}} 28000\right)$ was then sequenced.

Argos et al. (1981) used a series of algorithms to align the sequences of the L-arabinose- and D-galactose-binding proteins of $E$. coli so as to maximize the extent of homology between the two proteins over their entire length. By aligning these sequences with those of GBP1 and GBP2, it became clear that the $\mathrm{N}$-terminal sequence of the GBP1 fragment exhibited significant homology with an internal region of the arabinose-binding protein of $E$. coli (Fig. 1a). Similarly, the N-terminus of GBP2 shared significant regions of homology with both these $E$. coli proteins, particularly with the arabinose-binding protein (Fig. 1b). Two amino acid residues that have been implicated in the binding of arabinose and galactose (Argos et al., 1981; Henderson, 1986) were strongly conserved in GBP1 and GBP2; viz. an aspartate residue (D) in the $M_{\mathrm{r}} 28000$ fragment of GBP1 (which aligned well with asp89 of the arabinose-binding protein) and the glutamate residue (E) glu14 in GBP2 (which corresponded to glu14 of the arabinose-binding protein and to asp14 of the galactose-binding protein). Although no lysine residue (K) was present in GBP2 equivalent to the important lys 10 and lys 11 residues of the arabinose- and galactose-binding proteins respectively, gln 13 in GBP2 corresponded quite well with the important gln 11 residue in the arabinose-binding protein.

These limited sequence data therefore indicated that both GBP1 and GBP2 from $A$. radiobacter possess some features in common with the arabinose- (and galactose-) binding proteins of $E$. coli. However, it should be noted that antiserum raised against GBP1 did not cross-react with GBP2 and vice versa (see below), thus indicating that the two glucose-binding proteins have few, if any, common epitopes.

\section{Glucose transport by $A$. radiobacter $A R 9$ and $A R 18$ following batch growth on different carbon sources}

The glucose uptake rates of washed cells of $A$. radiobacter AR18 and AR9 were measured following growth in batch culture on different carbon sources (Table 2). The rates exhibited by strain AR 18 varied by approximately threefold (glucose $<$ sucrose/galactose/xylose $<$ succinate $<$ fructose $<$ maltose $<$ glycerol $<$ gluconate $<$ lactose), the rate following growth on lactose being close to that exhibited by cells grown under glucose limitation in continuous culture $\left(D 0.045 \mathrm{~h}^{-1}\right)$. SDS-PAGE of cell samples, followed by protein staining using Kenacid Blue and by Western blotting using antibodies raised against GBP1 or GBP2 (Fig. 2), indicated that GBP2 was virtually absent from strain AR18 except following growth on gluconate or lactose (not shown), and that the variation in the glucose uptake rate therefore principally reflected the variable repression of GBP1 during growth on different substrates.

The glucose uptake rates exhibited by strain AR9 also varied substantially depending on the carbon source, but in a different order to strain AR18 (succinate < xylose/glycerol/fructose < 

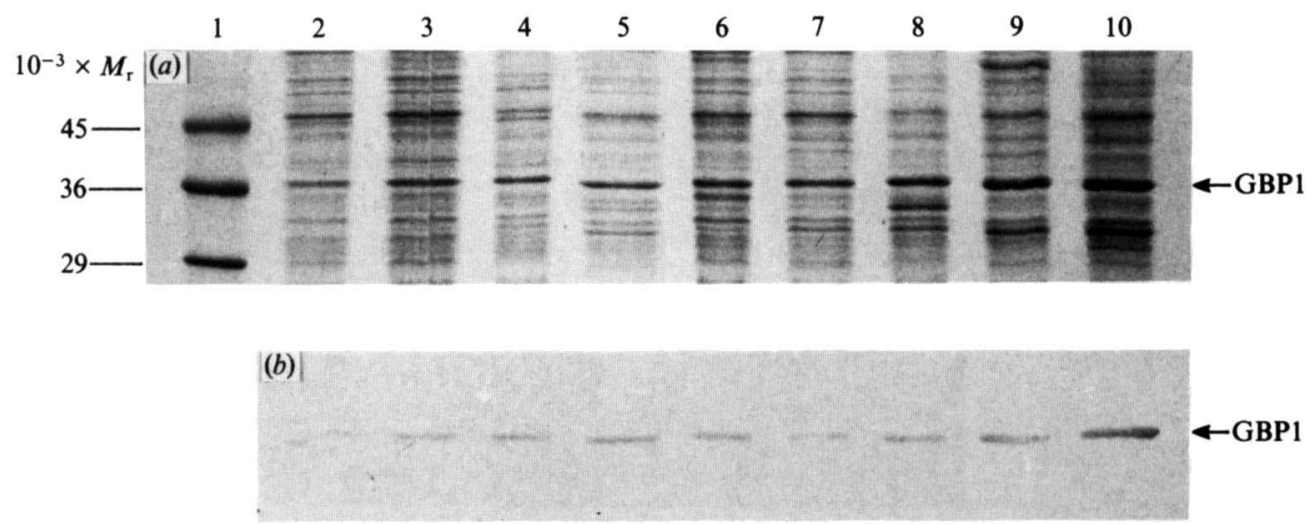

(c)

Fig. 2. Production of GBP1 and GBP2 by $A$. radiobacter AR18 during batch growth on different carbon sources as revealed by SDS-PAGE and Western blotting. Strain AR18 was grown at $\mu_{\max }$ in batch culture on a minimal medium containing different carbon sources. Cellular proteins were separated using SDS-PAGE and either stained with Kenacid Blue $(a)$ or transferred onto nitrocellulose and then probed using antiserum raised against GBP1 $(b)$ or GBP2 $(c)$. Tracks: $1, M_{\mathrm{r}}$ standards; 2, glucose; 3 , galactose; 4, xylose; 5 , sucrose; 6 , succinate; 7 , maltose; 8 , fructose; 9 , glycerol; 10 , gluconate.

Table 2. Glucose uptake by washed cells of A. radiobacter ARI8 and AR9 following growth in batch culture on various carbon sources

Cells were harvested during the exponential growth phase, and prepared and assayed for glucose uptake as described in Methods. The two strains grew at equal rates and exhibited $\mu_{\max }$ values of $0.35 \pm 0.05 \mathrm{~h}^{-1}$ except for growth on lactose $\left(0.43 \mathrm{~h}^{-1}\right)$ and glycerol $\left(0.27 \mathrm{~h}^{-1}\right)$.

$\begin{array}{lccc}\begin{array}{c}\text { Growth } \\ \text { substrate }\end{array} & \overbrace{\text { AR18 }}^{\begin{array}{c}\text { Glucose uptake rate } \\ \text { [nmol } \text { min }^{-1}\left(\mathrm{mg} \mathrm{cells}^{-1}\right]\end{array}} & \begin{array}{c}\text { AR9 } \\ \text { Relative rate } \\ \text { (AR18/AR9) }\end{array} \\ \begin{array}{l}\text { Glucose } \\ \text { Sucrose }\end{array} & 22 \pm 1(5) & 23 \pm 1(5) & 0.96 \\ \text { Galactose } & 31 \pm 3(3) & 26 \pm 2(4) & 1.19 \\ \text { Xylose } & 32 \pm 5(3) & 31 \pm 4(3) & 1.03 \\ \text { Succinate } & 33 \pm 6(3) & 20 \pm 1(3) & 1.65 \\ \text { Fructose } & 36 \pm 1(3) & 9 \pm 0(3) & 4.00 \\ \text { Maltose } & 41 \pm 5(3) & 21 \pm 2(3) & 1.95 \\ \text { Glycerol } & 45 \pm 2(3) & 25 \pm 1(3) & 1.80 \\ \text { Gluconate } & 51 \pm 1(3) & 20 \pm(2) & 2.55 \\ \text { Lactose } & 62 \pm 6(3) & 23 \quad(2) & 2.70 \\ \text { Glucose-limitation } & 67 \pm 6(3) & 33 \pm 4(3) & 2.03 \\ \left(D 0.045 \mathrm{~h}^{-1}\right) & 69 \pm 3(11) & 54 \pm 3(7) & 1.28\end{array}$

glucose/gluconate $<$ maltose/sucrose $<$ galactose/lactose). In all cases, the glucose uptake rate was equal to or less than the rate exhibited by strain AR 18 following growth on the same carbon source. The rate was particularly low following growth on succinate, and even on lactose was well below that exhibited by cells grown under glucose limitation in continuous culture. SDS-PAGE and Western blotting (Fig. 3) indicated that both GBP1 and GBP2 were present in 

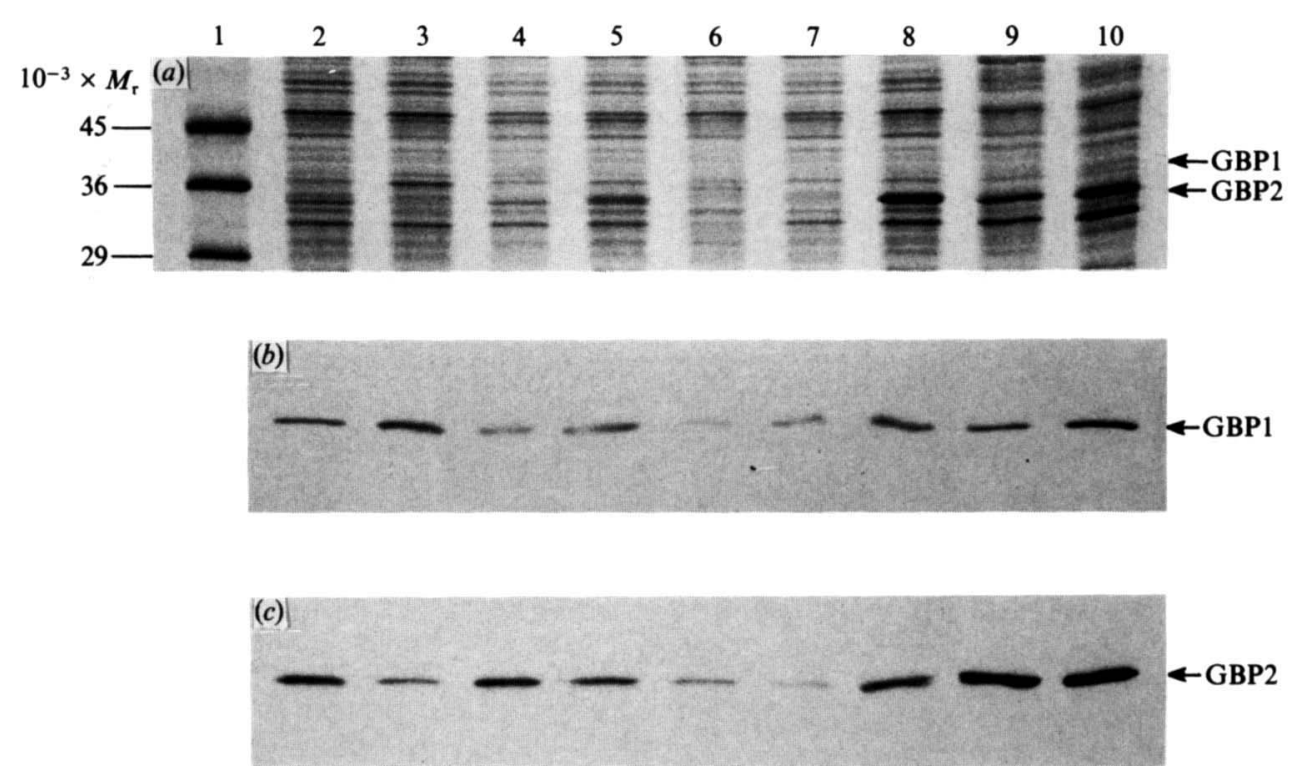

Fig. 3. Production of GBP1 and GBP2 by $A$. radiobacter AR9 during batch growth on different carbon sources as revealed by SDS-PAGE and Western blotting. Strain AR9 was grown as described in the legend to Fig. 2. Cellular proteins were separated using SDS-PAGE and either stained with Kenacid Blue $(a)$ or transferred on to nitrocellulose and then probed using antiserum raised against GBP1 $(b)$ or GBP2 (c). Tracks, as Fig. 2.

strain AR9. The concentrations of both proteins varied with the carbon source, the concentration of GBP2 being higher than that of GBP1 except following growth on galactose or maltose (the apparently very high concentration of GBP2 following growth on fructose was not reflected in the Western blot, and subsequent experiments showed that although it was a periplasmic protein it was not GBP2). It is likely, therefore, that the variation in the glucose uptake rate of strain AR9 generally reflected the combined repression of GBP1 and GBP2, but principally that of GBP2. However, this was clearly not the case with cells grown on maltose, thus raising the possibility that the maltose uptake system may also transport glucose. These results lend further support to the view that the expression of GBP1 by $A$. radiobacter is less strongly regulated than the expression of GBP2 (Cornish et al., 1988a).

\section{Galactose and xylose transport by $A$. radiobacter ARI8 and AR9 following batch growth on glucose}

The rates of glucose, galactose and xylose uptake by washed cells of $A$. radiobacter AR18 and AR9 were measured following growth in batch culture with glucose as the carbon source. No significant differences in the rates of glucose uptake were observed between the two strains (see Table 2). However, the rate of galactose uptake was very much faster in strain AR18 than in strain AR9 [19 cf. $8 \mathrm{nmol} \mathrm{m^{-1 }}$ (mg cells) $)^{-1}$ ], which was commensurate with the observations that galactose was bound much more strongly by GBP1 than by GBP2, that the $K_{\mathrm{D}}$ of GBP2 for galactose was much higher than the concentration of galactose in the uptake assay, and that GBP1 was present at a much higher concentration in strain AR18 than in strain AR9 (see Table 1, Figs 1 and 2; also Cornish et al., 1988a). In contrast, the rate of xylose uptake by the two strains was essentially the same [16 cf. $15 \mathrm{nmol} \mathrm{min}^{-1}(\mathrm{mg}$ cells)-1]. This was a somewhat unexpected result in view of the observations that GBP2 found xylose much more strongly than GBP1 and was also present at a much higher concentration in strain AR9 than in strain AR18. However, it appears that these properties were offset by the fact that the $K_{\mathrm{D}}$ of GBP1 for xylose, although high, was substantially lower than the concentration of xylose in the assay, and that strain AR18 contained a substantial amount of GBP1. 

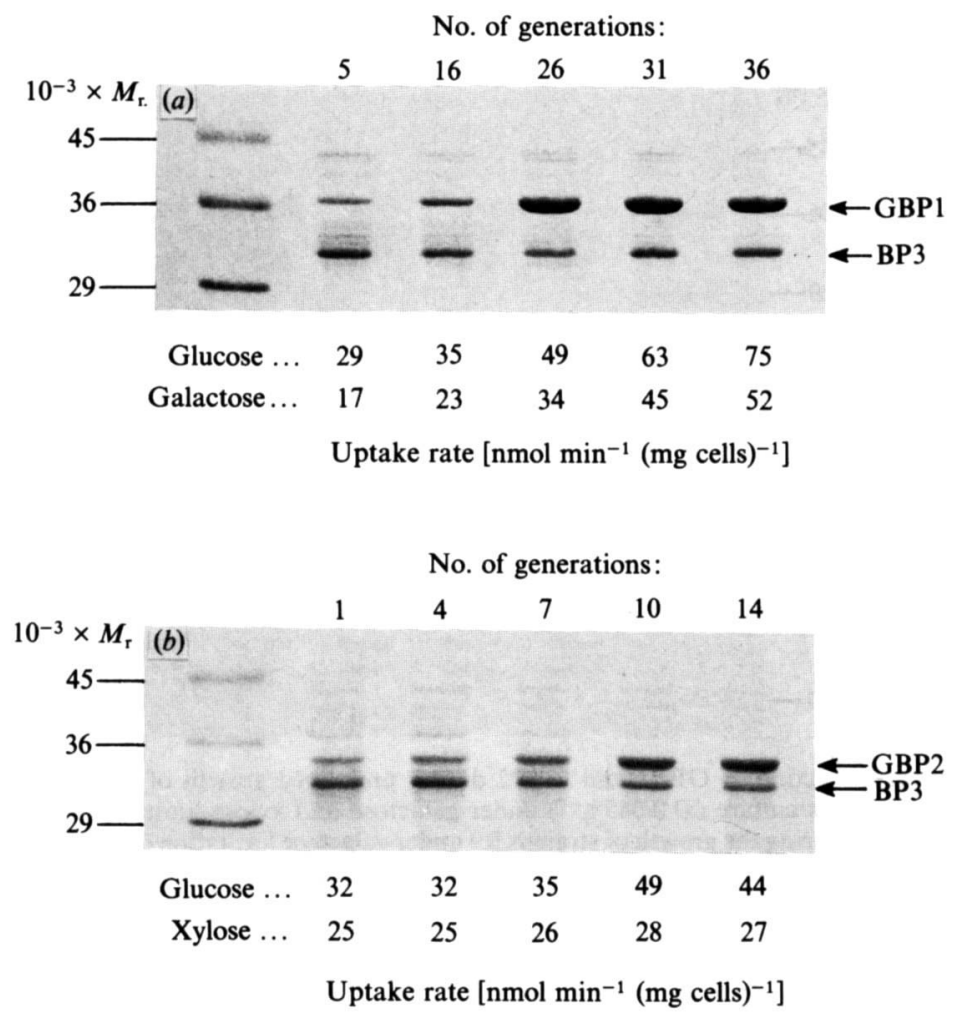

Fig. 4. Hyperproduction of GBP1 and GBP2 following prolonged growth of wild-type $A$. radiobacter in continuous culture $\left(D 0.045 \mathrm{~h}^{-1}\right)$ under galactose and xylose limitation. Cell samples were taken at intervals during growth under galactose limitation $(a)$ or xylose limitation $(b)$ and protein profiles were analysed using SDS-PAGE. Tracks: $1, M_{\mathrm{r}}$ standards; 2-6, cell samples.

\section{Selection of new strains of A. radiobacter that hyperproduce GBP1 or GBP2 following prolonged} growth in continuous culture ( $\left.D 0.045 h^{-1}\right)$ under galactose or xylose limitation

It was noted previously that $A$. radiobacter responded to the strong selective pressures imposed during growth under glucose limitation for approximately 20 generations by simultaneously segregating into two strains that hyperproduce either GBP1 (strain AR18) or GBP2 (strain AR9), but not both (Cornish et al., 1988a). Furthermore, the studies reported above indicated that GBP1 and GBP2 also exhibited high affinities for galactose and xylose respectively and hence may be specifically involved in the transport of these substrates during growth under galactose and xylose limitation. These possibilities were tested by growing the parent strain of $A$. radiobacter in continuous culture $\left(D 0.045 \mathrm{~h}^{-1}\right)$ for a prolonged period under either galactose or xylose limitation, the expectation being that only those binding proteins which were specifically involved in taking up the growth-limiting substrate would become hyperproduced.

Glucose and galactose uptake rates of washed cells increased substantially during growth under galactose limitation, as also did the concentration of GBP1 but not GBP2 (Fig. 4a). Single-colony analysis done at the end of the selection period showed that the culture was homogeneous, and that it also hyperproduced GBP1 during batch growth on glucose. It therefore resembled strain AR18 that had previously been selected by growth under glucose limitation (Cornish et al., 1988a); however, as this culture was isolated following growth under galactose limitation it was subsequently called strain AR18a.

Similarly, the glucose uptake rate of washed cells increased substantially during growth under xylose limitation, as also did the concentration of GBP2 but not GBP1 (Fig. 4b). These changes were accompanied by a slight increase in the xylose uptake rate. This culture was similar to 

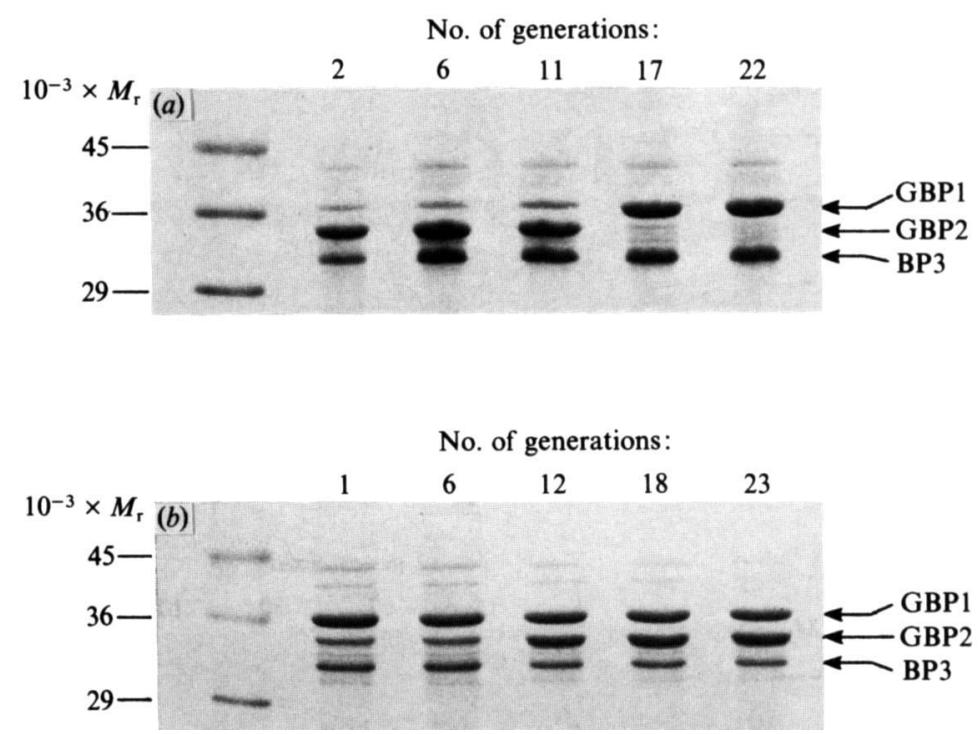

Fig. 5. Hyperproduction of GBP1 and GBP2 during prolonged growth of $A$. radiobacter AR9 and AR 18 in continuous culture $\left(D 0.045 \mathrm{~h}^{-1}\right)$ under galactose and xylose limitation. Cell samples were taken at intervals during the growth of strain AR9 under galactose limitation (a) and strain AR 18 under xylose limitation $(b)$ and protein profiles were analysed using SDS-PAGE. Tracks, as Fig. 4.

strain AR9, but as it was isolated during growth under galactose rather than glucose limitation it was called strain AR9a; it was not subjected to colony analysis.

The results of these in vivo selection experiments are consistent with the proposal that GBP1 is involved in the transport of D-glucose and D-galactose, whereas GBP2 is involved in the transport of D-glucose and D-xylose. In order to test this hypothesis further, $A$. radiobacter strains AR9 and AR 18 were grown for more than 20 generations under galactose limitation and xylose limitation respectively; under these conditions the production of large amounts of superfluous transport proteins (GBP2 in strain AR9, and GBP1 in strain AR18) would be expected to be disadvantageous, and the capacity to hyperproduce them ought therefore to be lost.

As predicted, the phenotype of strain AR9 changed dramatically during growth in galactoselimited continuous culture $\left(D 0.045 \mathrm{~h}^{-1}\right)$ (Fig. 5a). Although significant amounts of GBP2 were produced initially, indicating that this glucose transport system is induced by galactose as well as by glucose, GBP2 was eventually replaced by GBP1. Single-colony analysis at the end of the selection period revealed that the culture was homogeneous. The new strain thus resembled strains AR18 and AR18a, and this conclusion was reinforced when it was shown to produce more GBP1 than GBP2 during batch growth on glucose.

Conversely, when strain AR18 was grown under xylose limitation, although the concentration of GBPl remained relatively high the concentration of GBP2 increased significantly and eventually exceeded that of GBP1 (Fig. $5 b$ ). Single-colony analysis at the end of the selection period revealed that the culture was again homogeneous. The new strain thus showed some similarity to strain AR9; however, unlike strain AR9, it produced more GBP1 than GBP2 during batch growth on glucose (indicating that excess glucose continued to repress GBP2 much more strongly than GBP1). As growth under xylose limitation did not lead to a rapid loss of GBP1, it seems likely either that GBP1 has a role in xylose transport (not withstanding the high $K_{\mathrm{D}}$ value of this protein for D-xylose in vitro) or, more plausibly, that the mutations needed to switch off hyperproduction of GBP1 occur relatively infrequently.

It should be noted that all of these selected cultures produced similar amounts of BP3 during carbon-limited growth (after allowing for slight variations in the gel loadings), irrespective of the nature of the carbon source (glucose, galactose or xylose) and the duration of the selection period. 

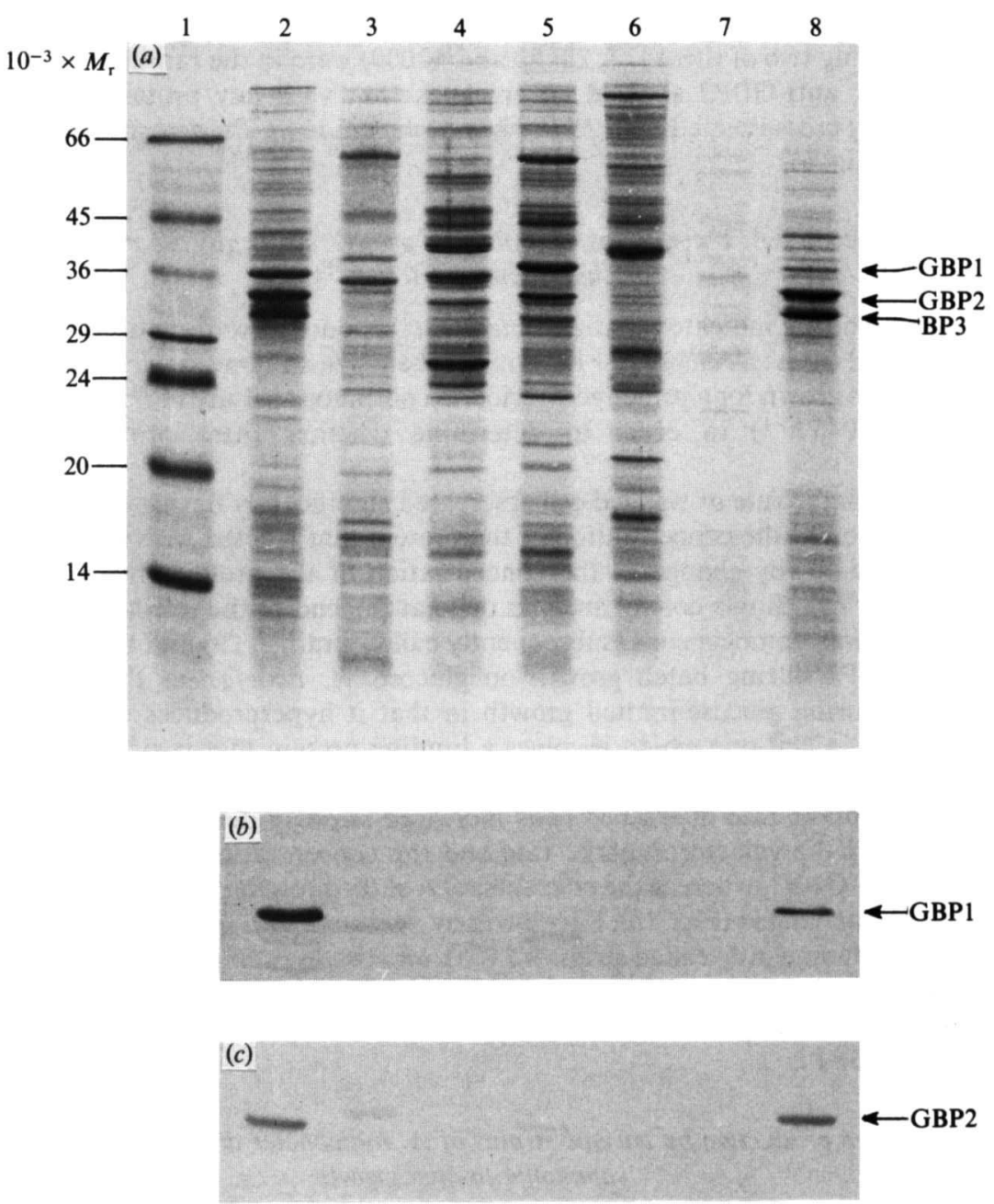

Fig. 6. Screening of various Gram-negative bacteria for proteins capable of cross-reacting with antisera raised against GBP1 and GBP2 from $A$. radiobacter. Bacteria were grown in glucose-limited fed-batch culture $\left(\mu 0 \cdot 10 \mathrm{~h}^{-1}\right)$, except for $A$. radiobacter and $A$. tumefaciens which were grown in glucose-limited continuous culture $\left(D 0.045 \mathrm{~h}^{-1}\right)$. Cell proteins were separated using SDS-PAGE, then either stained with Kenacid Blue $(a)$ or transferred to nitrocellulose and probed with antiserum raised against GBP1 $(b)$ or GBP2 $(c)$. Tracks: $1, M_{\mathrm{r}}$ standards; 2, A. radiobacter; 3, E. herbicola; 4, E. coli; $5, K$. pneumoniae; $6, X$. campestris; $7, R$. leguminosarum $; 8$, A. tumefaciens.

Screening of various Gram-negative bacteria for proteins capable of reacting with antisera prepared against $G B P 1$ and $G B P 2$

In order to establish whether proteins similar to GBP1 and GBP2 are produced by other Gram-negative bacteria, organisms representative of the Rhizobiacae, Enterobacteriaceae and Pseudomonadaceae families were grown on minimal media in glucose-limited fed-batch culture $\left(\mu 0.10 \mathrm{~h}^{-1}\right)$ or continuous culture $\left(D 0.045 \mathrm{~h}^{-1}\right)$ in order to derepress glucose transport. Cells were then screened using Western blotting for the presence of proteins that cross-reacted with antisera raised against GBP1 and GBP2 from $A$. radiobacter.

Anti-GBP1 and anti-GBP2 cross-reacted respectively with GBP1 $\left(M_{\mathrm{r}} 36500\right)$ and GBP2 ( $M_{\mathrm{r}} 33500$ ) produced by $A$. radiobacter, and also with proteins of similar $M_{\mathrm{r}}$ to GBP1 and GBP2 produced by $A$. tumefaciens (Fig. 6). In contrast, both antibodies cross-reacted only weakly with single proteins produced by $E$. coli $\mathrm{K} 12$, Klebsiella pneumoniae and Erwinia herbicola 
$\left(M_{\mathrm{r}} 33000-36000\right)$. Anti-GBP1 also cross-reacted weakly with several proteins in Xanthomonas campestris, but only two of these $\left(M_{\mathrm{r}} 28000\right.$ and 40000$)$ were in the range expected for a sugarbinding protein; anti-GBP2 showed no cross-reaction with any proteins in this organism. Neither antibody cross-reacted with Rhizobium leguminosarum, Ps. aeruginosa or Ps. mendocina (not shown in Fig. 6).

\section{Adaptation of A. tumefaciens to prolonged growth under glucose and galactose limitation $\left(D 0.045 h^{-1}\right)$}

As Western blotting indicated that $A$. tumefaciens produced two proteins that were similar to GBP1 and GBP2 from $A$. radiobacter in terms of their size and immunological cross-reactivity, the organism was grown for a prolonged period in continuous culture under glucose or galactose limitation $\left(D 0.045 \mathrm{~h}^{-1}\right)$ in order to determine whether these proteins could also be hyperproduced.

The glucose uptake rate of washed cells increased significantly during growth under glucose limitation, as also did the concentration of the protein that reacted with anti-GBP2, but there was no evidence of any change in the concentration of the protein that cross-reacted with anti-GBP1 (Fig. 7a). Single-colony analysis done at the end of the selection period confirmed that the culture was homogeneous (subsequently called strain AT9) and that it produced more GBP2 than GBP1 during batch growth on glucose. A. tumefaciens therefore differs from $A$. radiobacter during glucose-limited growth in that it hyperproduces only a single glucose transport system, albeit one which involves a binding protein that is similar to (and possibly identical with) GBP2 from $A$. radiobacter.

The glucose uptake rate of washed cells increased strongly during growth under galactose limitation, as did the galactose uptake rate and the concentration of the protein that crossreacted with anti-GBP1, whereas the concentration of the protein that cross-reacted with GBP2 was essentially unchanged (Fig. $7 \mathrm{~b}$ ). Single-colony analysis again indicated that the culture was homogeneous (subsequently called strain AT18a), and that it produced more GBP1 than GBP2 during batch growth on glucose. A. tumefaciens therefore behaves similarly to A. radiobacter during galactose-limited growth in that it hyperproduces a protein that is similar to (or even identical with) GBP1.

\section{Succinoglucan production by various strains of $A$. radiobacter and A. tumefaciens during ammonia-limited growth}

Previous work from this laboratory has shown that A. radiobacter AR18 (which hyperproduces GBP1 during glucose-limited growth) converted glucose into succinoglucan during ammonia-limited growth at a higher rate than either the parent strain or strain AR9 (which hyperproduces GBP2 during glucose-limited growth) (Cornish et al., 1988b). Similarly, the GBP1-hyperproducing strain of $A$. radiobacter (strain AR18a) that was isolated during the present work following prolonged growth under galactose limitation, also produced succinoglucan at a significantly higher rate than the parent strain or strain AR9 during ammonia-limited growth on glucose (Table 3). Interestingly, however, no increase was observed in the rate of succinoglucan production from galactose (e.g. A. radiobacter strain AR18a and the parent strain both exhibited a rate of $0.21 \mathrm{~g} \mathrm{~h}^{-1}(\mathrm{~g} \text { dry wt})^{-1}$, which suggests that the overall rate of exopolysaccharide synthesis from galactose, unlike the rate from glucose, was not determined primarily by the activity of the transport system.

In contrast to $A$. radiobacter, both of the newly isolated strains of $A$. tumefaciens (strains AT18a and AT9) produced succinoglucan from glucose at approximately the same rate as the parent strain during growth under ammonia limitation. It must be concluded therefore, either that the GBP1-dependent system of $A$. tumefaciens is more strongly repressed than the corresponding system in $A$. radiobacter during ammonia limitation, or that the flux control coefficient for glucose transport on succinoglucan production is lower in $A$. tumefaciens than in $A$. radiobacter (i.e. the rate of conversion of glucose into succinoglucan is determined primarily by the activity of some enzyme other than the glucose transport system). 
No. of generations:

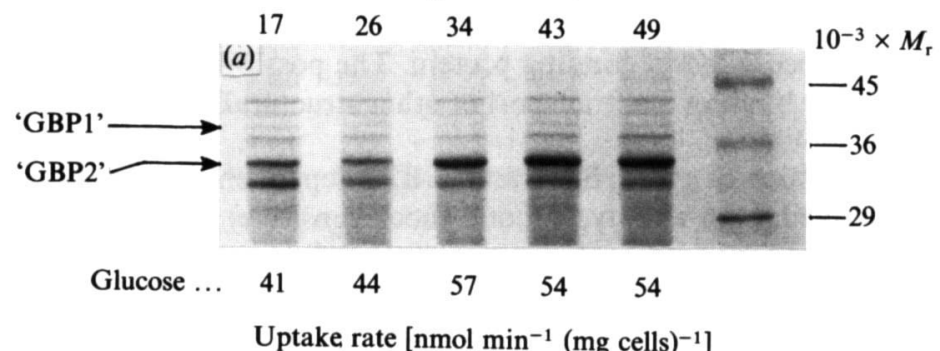

Uptake rate $\left[\mathrm{nmol} \mathrm{min}^{-1}(\mathrm{mg} \text { cells })^{-1}\right]$

No. of generations:

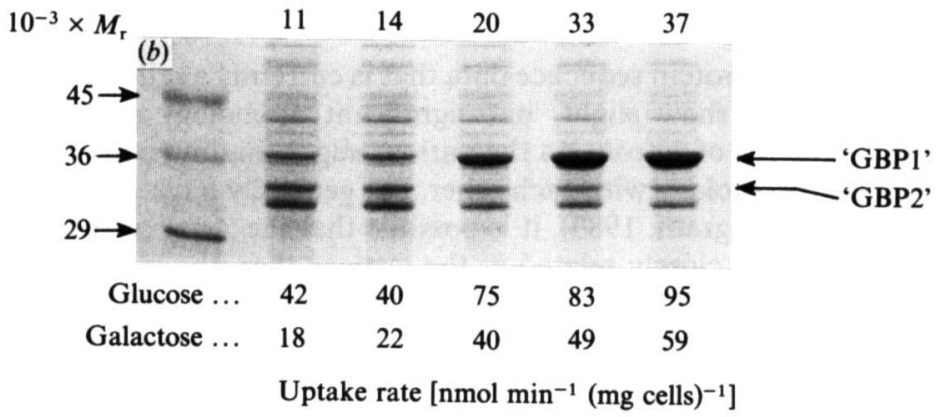

Fig. 7. Hyperproduction of putative sugar-binding proteins during prolonged growth of $A$. tumefaciens in continuous culture $\left(D 0.045 \mathrm{~h}^{-1}\right)$ under glucose and galactose limitation. Cell samples were taken at intervals during growth under glucose limitation $(a)$ and galactose limitation $(b)$, and protein profiles were analysed using SDS-PAGE. Proteins marked 'GBP1' and 'GBP2' reacted with antisera raised against GBP1 and GBP2 from $A$. radiobacter. (a) Tracks $1-5$, cell samples; $6, M_{\mathrm{r}}$ standards. (b) Track 1 , $M_{\mathrm{r}}$ standards; $2-6$, cell samples.

Table 3. Rates of production of succinoglucan from various strains of $A$. radiobacter and

A. tumefaciens during growth on glucose in continuous culture $\left(D 0.045 \mathrm{~h}^{-1}\right)$ under ammonia limitation

Novel strains of $A$. radiobacter and $A$. tumefaciens were isolated by growing the wild-type organisms under prolonged glucose or galactose limitation $\left(D 0.045 \mathrm{~h}^{-1}\right)$ as described in the text.

$\begin{array}{cllcc}\text { Organism } & \text { Strain } & \begin{array}{c}\text { Limitation } \\ \text { for strain } \\ \text { selection }\end{array} & \begin{array}{c}\text { Major } \\ \text { glucose-binding } \\ \text { protein }\end{array} & \begin{array}{c}\text { Rate of succinoglucan } \\ \text { production } \\ \text { [g h }\end{array} \\ \text { A. radiobacter } & \text { Parent } & \text { None } & \text { GBP2 wt) } & 0.21 \pm 0.01(3)^{*} \\ & \text { AR9 } & \text { Glucose } & \text { GBP2 } & 0 \cdot 21 \pm 0 \cdot 01(9)^{*} \\ & \text { AR18 } & \text { Glucose } & \text { GBP1 } & 0 \cdot 30 \pm 0 \cdot 01(11)^{*} \\ \text { A. tumefaciens } & \text { AR18a } & \text { Galactose } & \text { GBP1 } & 0 \cdot 29 \pm 0.01(3) \\ & \text { Parent } & \text { None } & \text { GBP2 } & 0 \cdot 18 \\ & \text { AT9 } & \text { Glucose } & \text { GBP2 } & 0 \cdot 18 \pm 0.01(3) \\ & \text { AT18a } & \text { Galactose } & \text { GBP1 } & 0 \cdot 18 \pm 0.01(3)\end{array}$

* Data reported previously (Cornish et al., 1988b); included here for comparison.

\section{DISCUSSION}

Previous work in this laboratory has demonstrated that $A$. radiobacter produces two periplasmic binding-proteins (GBP1 and GBP2) that bind D-glucose with high affinity and are involved in the active transport of this sugar (Cornish et al., 1988a,b). We have now established through the use of equilibrium dialysis that GBP1 and GBP2 additionally bind D-galactose and 
D-xylose respectively, both with high affinity. Taken together with the continuous culture studies, these results suggest that GBP1 should be regarded as a glucose/galactose-binding protein, and GBP2 as a glucose/xylose-binding protein. The possibility that GBP1 and GBP2 may also be involved in the binding and transport of other structurally related sugars cannot at present be excluded.

The biochemical properties of the GBP1- and GBP2-dependent transport systems from $A$. radiobacter (energy-linked, high-affinity, osmotic-shock-sensitive) are similar to those of the binding-protein-dependent sugar transport systems of $E$. coli (e.g. the maltose, L-arabinose, D-galactose, D-xylose and D-ribose systems) (Ames, 1986; Henderson, 1986). However, the latter appear to differ from the two $A$. radiobacter systems in that they generally transport only a single sugar in vivo (the same sugar that usually induces the transport system), and the pure binding proteins tend to display a strong preference for the physiological substrate in vitro. The galactosebinding protein of $E$. coli is a notable exception, however, since it binds both D-galactose and D-glucose with high affinity in vitro (Boos, 1974) and therefore resembles GBP1 from A. radiobacter.

The limited amount of protein sequence data that is currently available for GBP1 and GBP2 indicates that they both show slight, but significant, homology with the arabinose- and galactose-binding proteins of $E$. coli. As the various sugar-binding proteins from $E$. coli show only limited sequence homology with each other, but generally have similar three-dimensional structures (Quiocho \& Pflugrath, 1980), it is possible that the Agrobacterium and E. coli sugarbinding proteins are more closely related at the tertiary than the primary level.

The dual substrate-specificity of GBP1 and GBP2 allows the selection of novel strains of $A$. radiobacter that not only hyperproduce these two binding protein-dependent transport systems following prolonged growth under glucose limitation (strains AR18 and AR9 respectively; Cornish et al., 1988a), but that also specifically hyperproduce the GBP1dependent system following galactose limitation and the GBP2-dependent system following xylose limitation (strains AR18a and AR9a respectively). As this approach has proved successful with the analogous binding-protein-dependent systems that transport glucose and galactose in $A$. tumefaciens, it appears to be a very simple and reproducible method for identifying the binding protein for a particular sugar and for obtaining the protein in large amounts. Furthermore, there appears to be no a priori reason why it could not be used to hyperproduce other types of sugar transport systems, e.g. various proton-symport systems (including the lac system) and phosphoenolpyruvate-dependent phosphotransferase systems. Indeed, it has recently been shown through the use of metabolic control theory that strains of $E$. coli which overproduce $\beta$-galactoside permease have a selective advantage over the wild-type organism during growth under lactose-limitation (Dykhuizen et al., 1987).

The spontaneous hyperproduction of these binding-protein-dependent transport systems during growth in continuous culture is presumably a genotypic response to prolonged starvation, followed by natural selection of the most-fit mutant strain. The molecular basis of this response is currently unknown, although it is clearly based on spontaneous mutations which lead either to gene amplification or to enhanced promoter activity. Attempts to reverse this process by selection against a hyperproducing strain have met with mixed success, as evidenced by the rapid response of strain AR9 to prolonged growth under galactose limitation compared with the sluggish response of strain AR18 to prolonged growth under xylose limitation.

The GBP1-dependent transport system of $A$. radiobacter is clearly less susceptible than the GBP2-dependent system to repression by carbon substrates, including glucose itself. As a result, $A$. radiobacter strains AR 18 and AR18a synthesize succinoglucan from glucose at a faster rate than either the wild-type organism or strain AR9 during growth under ammonia limitation, thus supporting the view that glucose transport is a major kinetic control point for succinoglucan synthesis (see also Cornish et al., 1988b). The key to increasing the rate of succinoglucan production by this organism even further is therefore to derepress the GBP1-dependent glucose uptake system during ammonia-limited growth towards the rate expressed by glucose-limited cultures. Eventually, of course, some other enzyme involved in glucose catabolism or succinoglucan biosynthesis will replace glucose transport as the major kinetic control point for 
succinoglucan production, and no further increase in the rate of polymer production will be observed.

In contrast to the situation with $A$. radiobacter, neither of the strains of $A$. tumefaciens that hyperproduce the equivalent of the GBP1- and GBP2-dependent uptake systems during growth under carbon limitation (strains AT18a and AT9) show an increased rate of succinoglucan production from glucose under ammonia limitation. Whether this indicates a more complete repression of the GBP1-dependent system by excess carbon compared with $\boldsymbol{A}$. radiobacter, or that glucose transport is not a major kinetic control point for succinoglucan synthesis in this organism, has yet to be determined. It does show, however, that even two very closely related polysaccharide-producing organisms do not behave identically. For this reason, it would be unwise to assume that the conclusions drawn from the work of $A$. radiobacter necessarily apply to the production of other bacterial extracellular polysaccharides.

The authors are indebted to Mathew Davidson and John Keyte for carrying out the amino acid sequencing, to John Linton for useful discussions, and to Shell Research for financial support.

\section{REFERENCES}

AMEs, G. F.-L. (1986). Bacterial periplasmic transport systems: structure, mechanism and evolution. Annual Review of Biochemistry 55, 397-425.

Argos, P., Mahoney, W. C., Hermodson, M. A. \& HANEI, M. (1981). Structural prediction of sugarbinding proteins functional in chemotaxis and transport. Journal of Biological Chemistry 256, 4357-4361.

Boos, W. (1974). Bacterial transport. Annual Review of Biochemistry 43, 123-146.

Cornish, A., Greenwood, J. A. \& Jones, C. W. (1988a). Binding-protein-dependent glucose transport by Agrobacterium radiobacter grown in glucoselimited continuous culture. Journal of General Microbiology 134, 3099-3110.

Cornish, A., Greenwood, J. A. \& Jones, C. W. $(1988 b)$. The relationship between glucose transport and the production of succinoglucan exopolysaccharide by Agrobacterium radiobacter. Journal of General Microbiology 134, 3111-3122.

Dykhuizen, D. E., Dean, A. M. \& HaRTL, D. L. (1987). Metabolic flux and fitness. Genetics 115, 25-31.

HeNDERSON, P. J. F. (1986). Active transport of sugars into Escherichia coli. In Carbohydrate Metabolism in Cultured Cells, pp. 409-460. Edited by M. J. Morgan. New York: Plenum Press.

LAEMMLI, U. K. (1970). Cleavage of structural proteins during the assembly of the head of bacteriophage T4. Nature, London 227, 680-685.

Linton, J. D., Evans, M., Jones, D. S. \& Gouldney, D. N. (1987a). Exocellular succinoglucan production by Agrobacterium radiobacter NCIB 11883. Journal of General Microbiology 133, 2961-2969.
Linton, J. D., Jones, D. S. \& WoOdard, S. (1987b). Factors that control the rate of exopolysaccharide production by Agrobacterium radiobacter NCIB 11883. Journal of General Microbiology 133, 2979-2987.

Linton, J. D., Gouldney, D. \& WoOdard, S. (1988). The efficiency and stability of exopolysaccharide production from different carbon sources by Erwinia herbicola. Journal of General Microbiology 134, 1913-1921.

Matsudaira, P. (1987). Sequence of picomole quantities of proteins electroblotted on to polyvinylidene difluoride membranes. Journal of Biological Chemistry 262, 10035-10038.

Nobile, S., Baccino, D., Takagi, T. \& Deshusses, J. (1988). Purification and properties of the $\gamma$-butyrobetaine-binding protein from an Agrobacterium sp. Journal of Bacteriology 170, 5236-5240.

Quiocho, F. A. \& Pflugrath, J. W. (1980). The structure of D-galactoside-binding protein at $4 \cdot 1 \AA$ resolution looks like $\mathrm{L}$-arabinose-binding protein. Journal of Biological Chemistry 255, 6559-6561.

RYE, A. J., DROZD, J. W., JonEs, C. W. \& LiNTON, J. D. (1988). Growth efficiency of Xanthomonas campestris in continuous culture. Journal of General Microbiology 134, 1055-1061.

Towbin, H., Staehelin, T. \& Gordon, J. (1979). Electrophoretic transfer of proteins from polyacrylamide gels to nitrocellulose sheets: procedure and some applications. Proceedings of the National Academy of Sciences of the United States of America 76, $4350-4354$. 